\title{
International Volunteers as Empowerment Agents: Challenges and Opportunities of IDV Contributions to Women's Empowerment Programs in Partner Communities
}

\author{
Pascale Saint-Denis
}

\section{Introduction}

In recent decades the term "empowerment" has become increasingly popular in development discourse, making its way to the top of the aid agenda. The growing prominence of empowerment programming has led to transnational actors engaging in programming intended to enhance empowerment among marginalized populations, or in some cases, development actors have been tasked with 'empowering others'. As 'empowerment agents', aid workers, including international development volunteers (IDVs), are actively involved in several strategies to promote local empowerment. The central focus of this paper is uncovering the nature of that empowerment work, and the successes and challenges associated with transnational actors in empowerment activities. Research drawing on 150 interview findings in 10 countries in the Global South uncovered substantial qualitative information about how partner organizations and recipient communities in the Global South understand empowerment and the contributions of IDVs as transnational aid workers in the promotion of gender equality and women's empowerment (GEWE) programming.

In this paper, I argue that the nature of the empowerment contributions made by IDVs is shaped by broader global priorities and strategies that focus on a limited understanding of empowerment. Specifically, I contend that the potential role of IDVs as 'empowerment agents' is limited because empowerment is defined in narrow terms around economic development rather than political change. While examples of political empowerment are observed in some countries, there is a tendency to limit empowerment in neoliberal and superficial terms, such as economic advancement rather than systemic changes. As such, the empowerment approach employed does not promote a transformational approach to power relations and can also perpetuate relations of inequality through the imposition of western values or approaches that may not be embraced locally. However, empowerment-related interventions offered by IDVs can also open spaces for new conversations, providing opportunities for shifts in behaviours and attitudes in local communities with respect to gender equality and women's rights. These shifts take the shape of formal and informal knowledge exchange experiences, alongside some of the perceived benefits of economic empowerment programs. These challenges and 
opportunities are examined in greater detail in the findings and analysis sections below. First, I will summarize the significance - and implications - of empowerment programming emerging from scholarly literature. I return to these debates in the analysis to situate the findings from this study in the broader debates about the nature and impact of empowerment programming. The paper will then conclude with some recommendations and strategies for IDVs to enhance their roles within empowerment programming, such as investing in relationship-building practices and being well-versed in the partner country's social and historical context prior to their arrival.

\section{Literature Review}

Going back to its roots, 'women's empowerment' is an inherently political notion, "contingent on women organizing to demand and promote change" (Sen/Grown 1987: 22) regarding the "structures of gender subordination" (Sen/Grown 1987: 25). As goals and priorities shift within development practice, however, the conceptualization of 'empowerment' has become a catch-all term and even buzzword (Batliwala 2007; Cornwall/Brock 2005), frequently combined with 'gender equality' by development actors (Eyben/Napier-Moore 2009) as GEWE (gender equality and women's empowerment). The issue of 'empowerment' now being a loosely defined concept, and even tossed together with 'gender equality', is well exemplified by the fifth Sustainable Development Goal (SDG) implemented by the United Nations (UN). The title of the SDG in question, "Achieve gender equality and empower all women and girls", employs the term 'empower', but there is no specific sub-target dedicated to supporting women's political movements (UN 2020). This space for subjectivity that is allowed to exist in reference to the term across development organizations and agencies therefore poses a significant challenge for streamlining the empowerment programming agenda.

Although 'empowerment' initially evoked women's political mobilization, Eyben and Napier-Moore (2009) point to an additional modern significance attached to it: economic empowerment. As women's economic empowerment has gained prominence in intervention efforts, the "meanings of empowerment associated with solidarity and collective action are being crowded out" (Eyben/Napier-Moore 2009: 294). Stripped of its original political depth (Kabeer 1999; Batliwala 2007; Sen/ Grown 1987), women's empowerment programming has been re-imagined to fit an economic model, wherein women in the Global South are provided with the tools and knowledge through a technical and skills-based approach to generate revenue, thus allowing them to have improved agency and empower themselves (Cronin-Furman/Gowrinathan/Zakaria 2017).

Women's empowerment programs, delivered with the support of international development volunteers (IDVs), are often predicated on the micro-level economic 
model, and the opportunities for IDVs to insert themselves in local communities and assume the role of 'empowerment agents' are numerous. From facilitating employment opportunities to business development activities (WUSC 2018; Cuso International 2020), IDVs are encouraged to share their technical know-how and capacities to help women lift themselves out of poverty by getting jobs, designing business models or monetizing hobbies. Although these programs can admittedly be life-altering for women at the individual or even community level, they are "isolated from any possibility of collective political action," thereby effectively "exacerbate[ing] [women's] depoliticization" and "limiting the ability to achieve long-term political solutions" (Cronin-Furman/Gowrinathan/Zakaria 2017:10). As such, while acknowledging that individual women or groups of women can reap decent economic and material benefits from such economic empowerment programs, they merely apply a bandage to larger systemic issues. Kabeer highlights in her interpretation of empowerment "the interdependence of individual and structural change in processes of empowerment" while stressing that "structures shape individual resources, agency and achievements" (Kabeer 1999: 461), indicating that changes in the collective's lives are enabled through structural transformations. Despite these aspirational goals of empowerment in theory, in practice, 'empowerment' remains a diluted notion as women's lives and their conditions of their work are actively being depoliticized. The structures that uphold systemic issues of gender-based violence, inaccessibility to quality health care and socio-economic injustice are not being dismantled, but rather, they are being mitigated or may even be reinforced, by development efforts. The paper thus examines the role of IDVs in supporting different notions of 'empowerment' in their collaborative work with partner organizations and communities in the Global South.

Qualitative interviews with partner organization staff and program recipients provide rich insight into the experiences of working with IDVs in GEWE programming. The qualitative inductive thematic analysis of the study's findings points to three frames of analysis: 1) conceptualizations of empowerment; 2) implications for sustainability (long-term potential); and 3) prospects for reinforcing systems of inequality.

\section{Methods}

Interviews were conducted in 2018 - 2019 with 150 partner organization staff in ten countries. Once all interviews were transcribed, data were coded to identify common themes throughout. Data were analyzed using discourse analysis. This paper also draws on data from two focus groups with direct beneficiaries of Peruvian partner organizations. The introduction to this special edition has more detailed information on the methodology for data collection and the analysis of findings. 


\section{Findings}

Several significant findings emerged from the data that point to the principal contributions IDVs have made within local communities as empowerment agents. I first discuss the various positive behavioural and attitude transformations that have taken place with local community members as a result of IDV interventions. I then present the challenges associated with IDVs as empowerment agents in recipient communities.

\subsection{Shifts in Behaviours and Attitudes}

Respondents commonly identified behavioural and mindset transformations as a contribution of IDVs' engagement in empowerment programming efforts within the local communities. As empowerment agents, volunteers have contributed to changes that have taken place in direct recipients' attitudes regarding gender equality and women's rights. The contributions of IDVs include formal interactions and informal interactions including relationship building.

Organized activities such as workshops and training sessions with local women as part of empowerment programs allowed volunteers to share their knowledge on a wide range of themes such as women's health (particularly reproductive health), gender-based violence, education, and equity in the workplace. These spaces facilitated by IDVs allowed local community members to speak freely and reflect on these crucial topics. A staff member of a partner organization in Peru remarked how the volunteer had the capacity to fill in specific knowledge gaps in issues of gender equality as she "...manages very well the theme of everything that is gender equality, the gaps in gender as well, everything that had to do with the theme of household violence" which allowed her to develop and teach classes for a school of gender in collaboration with the partner organization. According to the interview respondents, the volunteers who designed and led such activities generally had some formal education or background in the field of feminist and gender studies. They also emphasized the value of involving male community members in these types of workshops and pieces of training to support pushing back on traditional gender roles and expectations. One male participant from a development NGO in Kenya stated how the training provided by an IDV in this area helped him become a better ally to women. He began by explaining why he personally benefited from the training, noting "I used to be that kind of traditional husband but this [volunteer] training really changed my approach and now I am a champion against such perceptions and there are many in this community who have embraced the value of having more independent and equal women."

One respondent from a Peruvian development NGO described the ease with which the IDV could translate academic feminist thought and theories into everyday 
conversations with their direct recipients. The participant explained that the work of translating concepts into daily activities is "an important challenge", adding that translating knowledge into daily life means considering gender relations and a "gender focus" in all relationships. IDVs are seen as transnational actors who can incorporate gender in their relationships "with other people, with our team, the litigations with the beneficiaries. It is noticeable that it is fluid for her."

The ways in which male community leaders treated women following collaborations with IDVs were said to have an especially positive influence on how other community members consequently treated women. The actions and words of these community leaders carry much more significance in their communities than those of international volunteers alone, as suggested by the following quote from a Malawian partner organization staff member who sees the importance of changes to mindsets of community members: "how the chief treats their women and how he does perform the gender roles, that can have more influence than [the] volunteer." The international volunteers whose placements focused on presenting information on taboo topics and prompting discussion in formal settings generally left a positive impression on beneficiaries and partner organization staff members. Respondents consider themselves to be more knowledgeable and comfortable discussing such topics and recognize their modified behaviours.

Participants repeatedly described the importance of day-to-day interactions and informal encounters with IDVs where they could converse candidly and discuss their personal lives with community members outside of partner organization programs were repeatedly reported by the participants. Such occasions included lunch meetings, sports, and other leisure activities. Creating these safe spaces was key to fostering trust between IDVs and the direct recipients, particularly the women, allowing them to share their lived experiences and be more open-minded to other's values and notions of womanhood and equality. The following quote from a Ugandan interviewee captures this mutual experience of relationship building: “... they [IDVs] freely interact with everyone and share their personal stories on their own experiences in life" and this is seen as empowering. When IDVs engage in "the daily interactions with the staff and other women, they can share that power of influence. So when they share their experiences, women are able to share back and based on those sharings interpersonally and learn from each other". These interactions are believed to have a significant impact on the participants and the community members. It is seen to enhance mutual learning and supports a mutually beneficial arrangement.

One Peruvian beneficiary also explained how the IDVs they worked with offered crucial support in their personal life outside of their work with the partner organization, which helped foster a strong bond between them. The friendship that emerged built between the IDV and partner organization staff member was viewed 
as highly rewarding. The participant highlighted how the IDV: "gives us advice, she helps us, she understood me, she helped me learned [sic] words I didn't [sic] understand. She helped me a lot by accompanying me in getting a job, when I got sick she accompanied me." The caring role of the IDV was considered important in both work and in personal spaces.

In contrast to the formal experiences of knowledge exchange, any volunteer with feminist values was considered capable of sharing these principles through relationship building, despite not having any education in feminist and gender studies. Other participants noted that while individual changes regarding feminist values and ideas of gender equality may not have been as prominent in their communities, the exposure to and interactions with volunteers still influenced some local women to think about pursuing new paths in their education and careers rather than continuing to live by the cultural gender expectations. This opinion was expressed by a staff member in a Kenyan development NGO in the following excerpt: "[The volunteers] won't make [the women] more outspoken, but they would make them to want to take an initiative to improve their lives like pursuing a diploma course...". The interventions by IDVs allow the community members to reflect on their options and create new opportunities for the girls in the community to consider applying for scholarships to go abroad for school". The impact is that "their mind is opened up; they are open minded."

This informal knowledge exchange was also not limited to the local women, as men and boys were also cited to have made strong bonds with male and female IDVs and experienced a change in how they perceive and perform gender roles. The following quote from a Malawian partner organization staff member reflects on how “... [the male volunteer] was a role model to the boys..." and encouraged them to take on tasks that defied conventional gender norms, such as cooking. They finally realized that "... nutrition issues are not only for the girls, [or for] women in the kitchen, it's for everyone."

The respondents additionally stated that those in the communities engaged in the different knowledge exchange experiences frequently shared their thoughts and reflections with other community members, particularly their friends and family. Opening this dialogue with others was considered paramount to making major strides towards the collective shift in mindset and mentality on women's rights and gender equality. One Peruvian beneficiary regarded this effect as empowerment and reflected on how it impacted her and those around her: "It could be that change that has impacted me so much, and I have been able to change and change the chip of others, empower other women only through discussion. They, in turn, empower their family." 
Investing in building trust with partner communities was considered an effective method for IDVs to engage with beneficiaries and better carry out their placements.

\subsection{Women's Economic and Material Gains}

In addition to the changes in mindsets at the personal and community level, the interviewees often reported economic, and material gains as notable IDV contributions. As part of women's economic empowerment programming, IDVs provided female recipients services intended to generate revenue. Partner organizations expressed that IDVs participated in labour insertion initiatives with beneficiaries, such as connecting with local employers, working on CVs, and preparing interviews. Other projects focused on entrepreneurship to support women in developing their small businesses. IDVs provided capacity building and skills training activities that touched on communications, such as designing and maintaining websites and promoting businesses and business management, including finances, developing budgets, and keeping inventory. A Senegalese partner described how the contributions of volunteers in financial management helped local women develop their businesses in different sectors by “.... [training them] on how to [introduce] revolving credit ... to develop tools that will allow them to properly manage their revolving credit" which led to them to "...[develop] income-generating activities."

IDVs also provided capacity building services tailored to the specific products of women-owned small businesses to boost product sales, such as in Nepal, where “... they taught packaging, how to do the marketing, they taught them for the product to...sell the product more than before because of the packing."

Partner organization staff emphasized how generating revenue acted as a catalyst for women's increased agency and independence in their households. Receiving an income as a result of their involvement with IDVs improved women's roles as decision-makers in their homes and increased their self-confidence. Further, some local women who benefitted from these programs shared what they acquired with other women in the community so that more women could earn a better livelihood. Such was the case in Malawi where some volunteers assisted in creating different products from what a beneficiary groups of mothers cultivated from their garden who "are now able to come up with different snacks and they sell them out there. And also then they are now going out, teaching other mother groups from other surrounding schools."

\subsection{Challenges Associated with IDVs in Empowerment Programming}

While the data point to numerous positive contributions of IDVs concerning their engagement in empowerment programming, partner organizations also brought 
up the challenges and disadvantages associated with hosting IDVs. The two main challenges that respondents discussed were the imposition of Western notions and ideals of feminism and fostering discomfort in the local communities by challenging gender norms. Multiple partner organizations spoke about how they hosted some volunteers who consistently applied the standards of feminism and gender equality from their home countries to their new surroundings. This disconnect was attributed by partner organizations to a lack of open-mindedness or understanding of country context and was considered to be very problematic in IDV behaviours. The following excerpts from Peruvian and Ghanaian development NGO staff, respectively, acknowledge the differences in gender equality and equity according to social context and how they are not interchangeable:

I think that you can't import the concepts of gender equity that Canada would have that already works in that theme, it can't be directly imported here. The social differences between a Canadian woman and a Peruvian Indigenous woman, it's like from a different planet.

I have heard people talk about sometimes, in their cultural orientation in thinking about the issue [of gender equality] they want to wholesale it [their understanding of gender equality] on you and not recognizing the fact that, there are cultural issues that need to be respected.

Another Peruvian partner brought up their experience of white feminist ideals from IDVs, stating that "...the initiative, the fights of women, they have to leave from the same communities, the same women. It is not good that [the volunteers] come with Western impositions, with Western feminism, white feminism.” Attempting to impose Western conceptualizations of feminism and white feminism onto the local community members and within partner organizations also often led to unrealistic expectations and problematic saviour complexes.

Further, partner organizations reported that some of their IDVs made partner community members uncomfortable by challenging gender norms in a way that was considered disrespectful. These behaviours were generally exhibited by female volunteers who engaged in activities usually reserved for men, such as smoking and drinking. In other cases, female volunteers' clothing choices did not comply with the region's standards for how women dress, such as wearing short skirts and shorts. Some also insisted on discussing taboo subjects with very resistant groups, such as sex education, politics, religion, or gender equality in general. While these attitudes were probably typical in IDVs' home countries, they were considered improper or offensive in partner communities, especially by the local men. Partner organizations in Kenya frequently brought up this issue, one emphasizing how the community would reject the new ideas IDVs were trying to approach “....based on 
a single issue like [seeing the IDV] smoking...” or “...when [they] walk half [naked] like the way western countries are doing...”

By not adhering to the local norms of how women should dress and act, these female IDVs undermined their ability to build relationships with local men and women, which was thought to hinder the effectiveness of their placement's functions. Many partner organization staff communicated this issue to their international volunteers, who took the complaints into consideration and adjusted their actions, and others continued to disregard the discomfort of communities and partner organizations. It is worth noting, however, that in some cases, IDVs' privilege of being foreigners allowed them to push back on cultural norms and create a space for partner organizations to start a dialogue on issues they could not have previously discussed.

\section{Analysis}

To situate the impacts and challenges of IDVs detailed in the above findings within the literature, I will utilize the following three frames of analysis: conceptualizations of empowerment; challenges as they pertain to structural inequalities and colonial continuities; and opportunities for changing attitudes and behaviours. These will also be helpful in highlighting how this paper contributes to international volunteerism scholarship, specifically regarding impacts on women's empowerment programs in partner communities.

\subsection{Conceptualizations of Empowerment}

The study findings echo the literature regarding the different meanings ascribed to empowerment, as interviewees frequently used it in different contexts, thereby seemingly lending itself subjective to the speaker. The term was most often used to refer to women's self-confidence, agency, autonomy, or any general improvement in their quality of life. If we revisit the conceptualization of empowerment defined by Sen \& Grown, it is meant to be an emancipatory movement; a means to mobilize to bring an end to women's subjugation (1988). IDV empowerment programming should then primarily consist of placements supporting women's roles in activism, advocacy, and public policy. Indeed, some partner organization staff members and beneficiaries asserted that international volunteers were active in the political sphere as part of their mandate by helping organize campaigns, conducting capacity building activities with women in decision-making bodies, and working with state institutions and civil society organizations to push for policy changes (see Mpogazi in this volume for examples of political empowerment).

However, the participants described a wide range of different empowerment programs put in place by Volunteer Cooperation Agencies (VCP) with other partner 
organizations who have different objectives, operations, and results depending on the program's design. Given the evolution of empowerment programming in intervention efforts documented in the literature, it is unsurprising that the most common empowerment programs addressed by participants consisted of women's economic empowerment and empowerment through knowledge exchange. Therefore, although there were IDVs who supported local women in pushing for systemic change, they were not as frequently discussed during the interviews focussing on economic empowerment compared to their participation in other empowerment programs.

In some partner countries, it can be drawn from these findings that there is minimal focus on activism and advocacy for women's rights as a part of economic empowerment programs than programs that can demonstrate short-term relief and benefits. As a result, programs that are meant to aid local women in the process of economically empowering themselves may be indivertibly keeping them from mobilizing and taking space in the political world. It also indicates that there may be misaligned understandings of empowerment across partner organizations, their programs, and, subsequently, their objectives.

\subsection{Perpetuating Inequality and 'Ongoing Saviourism'}

Opportunities to build relationships of solidarity exist in IDV programming. However, these fall short, in part because of the broader systemic inequalities that persist through colonial continuities, reinforcing ideas that women in the Global South need to be "saved" by their Global North (often) white feminist counterparts. Global North values and feminist priorities are seen, in many examples in the findings, to be part of a neocolonial agenda through which norms and attitudes are forced onto Global South partners (Cronin-Furman/Gowrinathan/Zakaria 2017). It can also be understood as a gendered white saviour complex or imperial feminism, "which uses Western social and economic systems to judge and make pronouncements about how Third World women can become emancipated" (Amos/ Parmar 1984: 7). Such mentalities of global sisterhood exhibited by white female international volunteers are well exemplified in this study as partner organizations frequently denounced white feminist beliefs and impositions of Western feminist values from IDVs. There is already an inherent power differential in the relationship between IDVs and community members from partner countries, generally just by virtue of IDVs originating from Northern countries. The power dynamics at play are then exacerbated when we consider the intersecting identities and experiences that may render specific populations more marginalized within the various systems of oppression. They can then be further worsened by a lack of knowledge that volunteers may have about the systemic challenges local women face, a lack 
of understanding of the broader country context and history, and the mismanagement of expectations of their impacts.

The belief that white women are the saviours of racialized women in developing nations further victimizes and essentializes Global South women. It also promotes "othering" while reinforcing the white saviour complex that dictates that these women must be saved from their circumstances and surroundings. This process is also characteristic of the longstanding concern of IDVs preserving colonial continuities by subjugating the other's needs and priorities with the righteousness of their own intentions and ideas of what resembles an equal, functioning society (Heron 2007). Consider the following excerpt from Cronin-Furman, Gowrinathan, and Zakaria that reflects this concept: "This focus on the evils of local cultures and traditions has long served as an argument in favor of intervention as a moral duty, incumbent on feminists who want other, lesser women to be empowered" (2017: 7). Motivations such as this one vilifies local cultures as a justification of IDV interventions and are tainted with the colonial mindset of importing and imposing "cleaner" cultural practices and beliefs. If international volunteers believe that it is their responsibility to empower Southern women through their altruism, then empowerment objectives will not be met and gaps in equality will be maintained. Moreover, while VSOs and partner organizations need to examine all IDVs' motivations for taking part in empowerment programs, sending organizations can also be complicit in perpetuating a very dangerous narrative if we look at how some volunteer-sending programs are sold to the Western public. More specifically, narratives that reinforce "othering", essentialize women, and contribute to white saviour rhetoric of "empowering Global South women", can be compared to more transformative marketing messages from IDV-sending organizations that promote a collaborative process of mutual learning and exchange.

Regardless of their good intentions to share their knowledge with local women and support them in the fight for gender equality, Global North women, particularly white Global North IDVs, may walk a fine line between trying to rescue and trying to support, and between harming and helping (Heron 2007). Diversifying and complementing North-South IDV models with other volunteer programming such as South-South or local volunteering can help to reduce power relations and to further dismantle structures of inequality. Other opportunities for building a collaborative and partnership-oriented approach to GEWE are outlined in Sadat's paper (this edition), who discusses strategies some partner organization staff employed to enhance dialogue and discussion around culturally appropriate GEWE strategies.

It is important to note that the partner organizations that did not identify as a feminist organization also did not discuss strategies to work closely with local feminist groups or women's rights organizations. Feminists in the Global South have 
mobilized efforts for local initiatives to advance women's rights and develop strategies for gender equality long before its recent prioritization in the Global North. Similar commitments to the promotion of gender equality exist within the partner organizations, where feminist women's rights partners have fought for gender equality and pushed for national governments to sign on to international commitments that align with gender equality goals. As these feminist movements already have long existed in host countries, the perceptions of outsider perspectives, the western imposition of feminist values, and gender equality norms may be misdirected at IDVs. Therefore, this sensibility may rather reflect the lack of collaboration between development organizations and women's rights organizations, which ultimately hinders the capacity to effectively align goals and collective understandings of crucial notions and themes.

Despite these important considerations and critiques noted above, local Peruvian beneficiaries did not perceive these dynamics with the IDVs they had been in contact with, but generally described their interactions with IDVs as equal relationships and friendships. The perception of IDVs held by local beneficiaries may be influenced by their engagement with diverse models of volunteerism. For example, around half of international volunteers in Peru were South-South volunteers from Latin America, and some were members of the Canadian Latin American diaspora. The beneficiaries did not report any problems of feeling inferior to any international volunteers, including white volunteers from Canada. They instead showed appreciation for the quality of the services they received and the commitment that IDVs showcased. Thus, it is essential that we recognize the agency of the partner communities and document their experiences in their own words to better consider the nature and impact of IDVs in women's empowerment programming. In addition, some of the concerns noted by partner organizations are based on projected or imagined reactions by beneficiaries.

\subsection{Opening Spaces for Changes in Attitudes and Behaviours}

The interview data also revealed insights pertaining to the implications for the sustainability of IDVs' impacts as empowerment agents. For the purposes of this discussion, sustainability in the context of international volunteering refers to the degree to which IDV contributions can generate long-term positive outcomes and benefits, mainly once they have left the country and are no longer supporting partner organizations. As the empowerment programs presented by partner organizations in interviews differ in model and design, the sustainability of IDVs' contributions facilitated by these programs also varies. Evaluating contributions entail multiple challenges such as measuring the reach of the impact, the efficacy of partner organizations to deliver their services, and the role of IDVs in the delivery of services. 
Beneficiaries and partner organization staff members communicated how specific IDV contributions had a broad reach and managed to benefit individuals who had not even been in contact with the international volunteers. For instance, community members' mindset and behavioural transformations regarding gender equality and women's rights following interactions with the volunteers could be considered a long-term benefit. Respondents described that those who benefitted directly from informal and formal knowledge exchange commonly shared and replicated these practices within their circles to open a dialogue with friends, family, and other community members. Direct recipients felt more comfortable speaking to others about taboo topics such as feminism, gender-based violence, and equal rights. Notably, male recipients could subsequently identify and denounce inappropriate actions or comments from other men in the community, which is meaningful as they also hold significant influence over the men in their circles and together have the capacity to re-define masculinity. Direct recipients themselves became agents of change, even after the volunteers had finished their placements. As such, this ripple effect that emerges from the data indicates that there are indirect recipients further out into the community who profit from empowerment programs. Nevertheless, if IDVs cannot connect and form relationships with partner communities, this ripple effect will be stunted, such as in circumstances where IDVs disregarded local dress codes or imposed Western ideals.

Regarding capacity building activities for women's economic empowerment, numerous IDVs engaged in programs that supported local women by strengthening specific skillsets, finding employment opportunities, and managing their small businesses. As noted earlier in this paper, there are apparent, immediate economic, and material benefits for many women who participate in these types of programs. Despite these benefits, however, there is a risk that comes with such livelihood empowerment placements guided by short-term objectives, which is a possible dependency on DVs' services and support. Several Peruvian direct beneficiaries of economic empowerment programs indicated that they believed they would struggle to continue developing their skills once the IDVs they worked with completed their placements. This concern underscores the constant need for these empowerment agent placements to be filled and how the sustainability of economic empowerment outcomes is particularly fragile.

While these contributions have generally left positive impacts according to partner organization staff members and local beneficiaries, some functions will continuously need to be assumed by IDVs as the challenges they address in their placements can only be adequately fixed with action from State or local government. This shortcoming is especially true for vulnerable groups whose pressing needs must be met with systemic change. Skills and knowledge can be appropriated and replicated to benefit individuals and even communities in some cases, but they 
will not be the solution to high unemployment rates, high rates of gender-based violence and inadequate health and education systems. IDVs are thus limited as empowerment agents, and future scrutinization of empowerment programs objectives is necessary to evaluate how short-term results could be tied to partner organizations priorities regarding funding and donor relationships.

The interviews conducted with partner organization staff in the 10 countries included in this study and the interviews with local community beneficiaries in Peru provide a rich discussion of the opportunities and challenges that IDVs bring to gender equality and women's empowerment programming. There are clear concerns raised about issues that arise from perceptions of Global North feminist values and/or inappropriate presentations of gender roles. However, these concerns were discussed in relation to a broader set of opportunities that shape the way that relationships can be built over time through collaborative programming.

\section{Conclusion}

Overall, partner organizations and community members were mostly satisfied with IDVs' contributions to empowerment programming within local communities and cited several benefits of their engagement. Volunteers most commonly facilitated formal and informal knowledge exchange experiences which have been associated with modifying mentalities and behaviours regarding GEWE. As empowerment agents, the IDVs opened a dialogue and prompted conversations surrounding numerous taboo topics and influenced direct beneficiaries to adopt feminist values. In turn, numerous direct beneficiaries transmitted what they had learned to individuals within their sphere of influence, furthering the long-lasting effects of these benefits. Moreover, volunteers provided technical support as part of economic empowerment program placements, which has enabled local women to earn revenue through developing their small businesses and finding employment opportunities through labour insertion initiatives. These outcomes were then associated with improving women's status in their households and an increased sense of agency. However, the narrow conceptualizations of women's empowerment that guide the short-term objectives of economic empowerment programs are incoherent with long-term development efforts to address root causes of structural inequality.

Notwithstanding the positive impacts of international volunteers in GEWE programming, some partner organization staff members remain somewhat cautious of the presence and impact of IDVs due to a number of challenges and difficulties that were discussed in interviews and outlined in this paper. Notably, some IDVs were criticized for their Western beliefs of feminism and gender equality that were not compatible with the context of their host country. Partner organization staff conveyed that some volunteers were harsh to judge the socio-cultural reality of female community members and insisted on the morality of their beliefs as above 
that of the communities'. In a similar vein, numerous IDVs were said to be dismissive of local gender norms and expectations by engaging in inappropriate gendered behaviours or activities, ultimately offending local community members and causing tension. The analysis within shows how these challenges are results and symptoms of racial and gendered power dynamics manifested through a saviour narrative. However, the beneficiaries expressed far fewer concerns about IDVs imposing their values, raising questions about the perceptions held by partner organization staff. Further research is needed to explore this inconsistency in perspectives to better understand what are real and what are perceived impressions of IDVs engaged in gender equality and women's economic empowerment programming.

Partner organizations offer two recommendations to lessen the impacts of the abovementioned challenges and enhance IDVs roles as empowerment agents. First, partner organizations recommended that IDVs possess considerable knowledge of the host country's context, including its cultural history and social norms prior to their arrival (a theme that is common across several papers in this volume: see papers by Sadat, Rouhani, Mpogazi). Partner organizations should provide additional pre-departure training that focuses on country-specific information and language training, when necessary, as partner organization staff consider current pre-departure training to be inadequate for preparing IDVs for the field. Specifically, IDVs must be well-informed of the complex gendered dynamics of the communities. Second, in-country partner organization offices should give international volunteers more time upon arrival for cultural adaptation and acclimation to the new environment before beginning their placements. This time will also allow volunteers to begin investing in building relationships with the beneficiary community members, which will be central to mitigating the IDV saviour mentality. A third recommendation: to enhance the empowerment components of women's economic empowerment activities, IDVs and partner organizations need to collaborate with women's rights organizations and other organizations that are experts in political empowerment. Doing so will facilitate a deeper analysis of empowerment processes and contribute to broader political goals and addressing structural inequalities in line with the definitions of empowerment from the scholarship.

\section{Bibliography}

Amos, Valerie; Pratibha, Parmar (1984): Challenging Imperial Feminism. In: Feminist Review, no. 17 , pp. 3-19.

Bandyopadhyay, Ranjan; Vrushali, Patil (2017): 'The white woman's burden' - the racialized, gendered politics of volunteer tourism. In: Tourism geographies, vol. 19, no. 4, pp. 644657.

Batliwala, Srilatha (2007): Taking the power out of empowerment - an experiential account. In: Development in practice, vol. 17, no. 4-5, pp. 557-565, https://doi. org/10.1080/09614520701469559. 
Cornwall, Andrea; Brock, Karen (2005): What do buzzwords do for development policy? a critical look at 'participation', 'empowerment' and 'poverty reduction'. In: Third world quarterly, vol. 26, no. 7, pp. 1043-1060, https://doi.org/10.1080/01436590500235603.

Cronin-Furman, Kate; Nimmi, Gowrinathan; Rafia, Zakaria (2017): Emissaries of Empowerment. Colin Powell School for Civic and Global Leadership. http://www.deviarchy.com/ wp/wp-content/uploads/2017/09/EMISSSARIES-OF-EMPOWERMENT-2017.pdf (2.19.2021).

Cuso International (2020): Empowering Women and Girls. https://cusointernational.org/ our-focus/empowering-women-and-girls/ (2.27.2021).

Eyben, Rosalind; Napier-Moore, Rebecca (2009): Choosing Words with Care? Shifting meanings of women's empowerment in international development. In: Third world quarterly, vol. 30, no. 2, pp. 285-300, https://doi.org/10.1080/01436590802681066.

Heron, Barbara (2007): Desire for development. Whiteness, gender, and the helping imperative. Waterloo.

Kabeer, Naila (1999): Resources, Agency, Achievements: Reflections on the Measurement of Women's Empowerment. In: Development and Change, vol. 30, no. 3, pp. 435-464, https:// doi.org/10.1111/1467-7660.00125.

Sen, Gita; Grown, Caren (1988): Development, crises and alternative visions: third world women's perspectives. London, https://doi.org/10.4324/9781315070179.

United Nations (2020): Goal 5. Achieve gender equality and empower all women and girls. https://sdgs.un.org/goals/goal5 (2.22.2021).

WUSC (2018): Volunteer Reflections on Building Women's Economic Empowerment in Jordan. https://wusc.ca/volunteer-reflects-on-role-in-building-womens-economicempowerment-in-jordan/ (28.10.2021). 